\title{
BAJA CALIFORNIA Y SUS MISIONES EN LA DÉCADA DE 1780
}

\author{
POR
}

\author{
Alfonso Esponera Cerdán
}

\begin{abstract}
RESUMEN
En este artículo se analiza un documento hallado en el Archivo General de la Nación en Ciudad de México fechado el 12 de mayo de 1783. Escrito por el dominico Luis Sales ofrece una interesante visión sobre la tierra y las gentes de la península de Baja California.
\end{abstract}

Palabras ClAVE: Luis Sales. México. Vida cotidiana. Península de Baja California. Siglo XVIII.

\begin{abstract}
The current article studies a document found in the General Archive of the Nation in Mexico City, that is dated the $12^{\text {th }}$ of May 1783 . Written by the dominico Luis Sales, it offers an interesting vision about the land and the peoples of Low Californian Peninsula.
\end{abstract}

KEY WORDS: Luis Sales. Mexico. Daily life in Low Californian Peninsula. XVIII ${ }^{\text {th }}$ century.

Investigando sobre Luis Sales y su presencia en las últimas décadas del siglo XVIII en las actuales tierras mexicanas de la península de Baja California, he tenido oportunidad de consultar el hermoso Archivo General de la Nación en Ciudad de México. En esta Comunicación voy a centrarme en uno de sus documentos, elaborado por el dominico valenciano y fechado el 12 de mayo de 1783. Pieza de interés no sólo por quien lo suscribe, sino también por la visión de aquellas tierras y gentes que en él brinda, en eran parte coincidente con la 
que dará en sus Noticias de la Provincia de California, libro que publicaría en su ciudad natal diez años después ${ }^{1}$

\section{PERFIL BIOGRÁFICO DE LUIS SALES MARTÍN O.P. (1745-1807)²}

Había nacido en Valencia en 1745, cursó Latinidad en su Universidad durante el Año Académico 1760-61, e ingresado en el Real Convento de Predicadores el 23 de octubre de 1761, realizó en dicho Convento su formación como dominico y sacerdote.

Los jesuitas tuvieron que abandonar sus Misiones de Baja California el 3 de febrero de 1768, decidiéndose que se pusieran al frente de ellas los franciscanos y el 1 de abril tomaron posesión; el posterior 24 de Julio, los dominicos iniciaron las Gestiones en Madrid para que se les concediera el pertinente permiso para ir a misionar a tièrras de aquella península.

Concedida la petición y respondiendo a la convocatoria hecha en julio de 1770 en exclusividad a los dominicos españoles europeos ${ }^{3}$, Sales integró - junto con otros veintisiete- la primera barcada o Misión que el 20 de Junio de 1771 partió de España «con la condición expressa de que passados 10 años me podría retirar a la Provincia [dominicana de Aragón, que integraba» ${ }^{4}$, aludiendo a la denominada «ley del decenio» de la legislación indiana vigente. Sin tener por qué negar las motivaciones evangelizadoras, no hay por qué olvidar las de seguir una «carrera más rápida» para alcanzar méritos y Grados ${ }^{5}$, así como el interés económico personal.

1 Noticias de la Provincia de California. 3 Cartas (Valencia, Hermanos de Orga, 1794), lo citaré: Noticias. seguido de un número romano y de otro arábigo que indican la Carta y la página correspondientes. Hay una edición facsimilar publicada por V. RIBES IBORRA, en sus «Misioneros valencianos en Indias». T. II. Valencia 1989. pp. 17-320. Esta obra la he analizado en: «Las 'Noticias de la Provincia de California' (1794), de Luis Sales», en Hispania Sacra (en prensa).

2 Cfr. A. .Esponera Cerdan. Presencia del valenciano Convento de Predicadores en la América de la segunda mitad del XVIII: Fr. Luis de Sales o.p. (1745-1807) (Valencia 1997, 2-289). El primero que bosquejó su biografía fue J. P. FUSTER, Biblioteca Valenciana T. II (Valencia 1830, 295296) y el que señaló su faceta de orador, que no señalarán otros, B.S.CASTELLANOS DE LOSADA, Biografía Eclesiástica Completa. T. XXV (Madrid 1865, 70).

3 Esta significativa presencia exclusiva la he estudiado en: «Los 'dominicos europeos' y los 'dominicos americanos' a partir de 1770», en Escritos del Vedat XXIX (1999) (en prensa).

4 A.G.N. (México), Misiones 23, Sales al Virrey, (México 27.1.1789), 362-362r; cf. 360

5 Quizá también le estimuló el recuerdo y ejemplo de un tío suyo dominico, José Sales (1 6901726), quien embarcó para Filipinas en julio de 1712; de salud bastante débil, además de diversos ministerios misioneros, fue profesor dc Filosofía y Teología, muriendo con fama de santidad en Manila en 1726 (cf. J. TEIXIDOR, Necrologio de este Real Convento de Predicadores de Valencia. Devidas tiietiiorias a sus hijos nativos con evtension en los inas ilustres recogidas de monumentos antiguos ' $Y$ 
La obtención de méritos y Grados - PredicadorGeneral, Presentado en prédica, Maestro, etc.- - con todo lo que llevaban anexo, fue algo que preocupó a los religiosos desde hacía tiempo, pero el mecanismo de su concesión estaba perfectamente regulado y la estancia en Misiones era una vía para ello. ${ }^{6}$

También he señalado la posible preocupación económica. Y es que estaba establecido por la legislación vigente que la Corona abonase anualmente un sínodo de 350 pesos por cada Padre misionero en ejercicio. Y así en el Consejo de la Provincia de Santiago de México, a la que se incorporaron preceptivamente estos frailes, celebrado el 18 de mayo de 1772, determinó que el Procurador de las Misiones no pagaría dicho sínodo a los misioneros en metálico, sino que cada uno debía hacer una lista de sus necesidades y dársela al Procurador, quién debía obtener los artículos, pagarlos y enviarlos ${ }^{7}$.

Los hijos de Santo Domingo tomaron posesión de las Misiones californianas existentes el 12 de mayo de 1773. Nuestro valenciano llegará a Loreto el posterior 21 de setiembre a causa de una enfermedad que había padecido, apareciendo - según las asignaciones de los correspondientes Capítulos Provinciales- como misionero residente en la Misión de Nuestra Señora de Guadalupe hasta 1778, año en que pasará a la Misión San Francisco de Borja, si bien también trabajará en jurisdicción de la Misión del Santísimo Rosario. A partir de 1781 estará en la Misión San Vicente Ferrer —desde donde en 1783 firmará el informe objeto de este trabajo- será uno de los fundadores en 1787 de la Misión San Miguel Arcángel, en la que permanece hasta el final de su estancia americana.

Transcurrido el preceptivo decenio en las tareas misioneras, solicitó en diversas ocasiones regresar a España, pero sólo obtuvo el permiso el 6 de junio de 1789. Llegó a su ciudad natal en octubre del año siguiente, reintegrándose a su Comunidad dominicana. En ella transcurrió su vida posterior, labrándose cierta reputación como orador de prestigio en celebraciones litúrgicas de rele-

fidedignos [ ... ]Año 1773. Tomo 4., 328-33 1, en B.tJ.V. (Valencia), ms. 933; V. T. GoMEZ y A. ROBLES SIERRA, «Misioneros de la Provincia Dominicana de Aragón (Siglos XVI-XIX)», publicado en La Provincia Doniinicana de Aragón ' v la Evangeli,7ación del Nuevo Mundo. Valencia 1991, 173).

6 En esta misma línea, siendo además una clara expresión regalista, es la Cédula Real de mayo de 1795 en la que se les conceden ciertas gracias, privilegios y exenciones a los dominicos misioneros (cf. nuestros trabajos: «Misioneros dominicos en Filipinas en la España de fines del siglo XVIII», en Studilini XXXV (1995) 233-265; «Francisco Galisteo y la concesión de privilegios a los misioneros dominicos», en Communio XXIX (1996) 337-390).

7 En 1773 se comunicaba a los Provinciales de todas las Ordenes existentes en Indias una Real Cédula según la cual «los estipendios y sínodos señalados a los religiosos doctrineros, de cualquier Orden, se entreguen a éstos y no a sus Prelados» (cf. Archivo de la Provincia Dominicana de Argentina (Buenos Aires), Curatos, leg.7, p. 17, en el leg. 13, p. 47 hay otra Cédula similar de 1790). 
vancia. En 1794 publicó en Valencia su ya mencionado libro, con la finalidad de «[ofrecer] una breve descripción de aquellos terrenos [de Baja California], con una cabal noticia de los indios, sus costumbres, inclinaciones e idiomas; de los animales, peces, plantas, yerbas y demás; [ ... así como de] la conquista espiritual y temporal de aquel país, y las varias épocas de sus Misiones [especialmente, la dominicana] ${ }^{8}$. En este tiempo hizo gestiones ante el Consejo de Indias para acogerse a la concesión de títulos y privilegios a misioneros dominicos establecida en 1795, que finalmente logró. En un memorial que a tal efecto presentó al Consejo de Indias en octubre de $1798^{9}$ destaca:

\footnotetext{
«que sirvió en las Antiguas Californias y en las fronteras de los gentiles, poniendo en corriente a costa de infinitos trabajos el Pueblo de San Vicente, fundando después el de San Miguel, último de la California Antigua, con lo que consiguió la comunicación de ambas y abrió caminos nuevos, haciendo fácil, breve y libre de los insultos de los gentiles el de San Diego;

que en sus expediciones de embarcaciones, de terrenos y descubrimientos, padeció hambres, heridas y golpes;

conquistó caciques, sosegó alborotos de indios silvestres, sacó de su poder algunos que conducían al sacrificio;

consumió con los mismos indios 4.533 pesos fuertes del Sínodo que Vuestra Magestad le consignaba para su subsistencia;

y por último, lleno de accidentes regresó con superior permiso a su Convento de Valencia, en cuyo viage naufragó, perdiendo sus cortos bienes y logró salvarse en una tabla, llegando desnudo a las costas de la Antigua California;

y finalmente, que aún estaba deseoso de dar a luz una instrucción completa a los misioneros y otras noticias para el público, de que ya ha impreso en Valencia tres tomos que fueron revividos con aplauso universal».
}

Fue elegido Prior del Convento de la castellonense Segorbe hacia 1806, falleciendo el 10 de septiembre del año siguiente.

\section{SU INFORME DESDE MISIÓN SAN VICENTE FERRER DEL 12 DE MAYO DE $1783^{10}$}

El Presidente de las Misiones californias, Padre Miguel Hidalgo, dirigió en marzo de 1783 una circular solicitando «que cada uno de los Reverendos $\mathrm{Pa}$ -

\footnotetext{
8 Noticias, I 3.

9 A.G.I. (Sevilla), Guadalajara 587, cuadernillo que comienza Consejo de Yndias en Sala primera..., pp. 2-3.

10 Junto con los de otros ocho misioneros dominicos, se encuentra en A.G.N., Provincias Internas, v. 1, exp. 11, ff. 345v-346v, y está transcrito en A.B. NIESER, Las fundaciones misionales dominicas en Baja California 1769-1822. (Mexicali 1998, 400-403; utilizaré esta versión -de ahí que no lo indique en las notas-, pero cambiando en algunos párrafos su puntuación por considerarla más exacta).
} 
dres exponga, diga, manifieste y declare con sinceridad y verdad su parecer, dictamen o sentir» sobre - ahora serán ya palabras de nuestro valenciano«la felicidad o infelicidad de esta península y sus naturales, con todas aquellas circunstancias que puedan conducir al perfecto conocimiento de ella».

Su respuesta tiene el mismo estilo literario y visión de la realidad que sus posteriores Noticias, lo que confirma su autoría. Las opiniones que expresará no se refieren a toda la península, sino sólo a lo que conoció directamente. Precisamente dirá en uno de sus últimos párrafos: «ninguno es capaz de formar idea completa de cuanto llevo dicho sin verlo ni experimentarlo, no de paso y sin manejo de lo que son los naturales, sino muy de asiento y gobierno interior y exterior de todos ellos, con conocimiento práctico de sus naturales inclinaciones». Esta fuente de conocimiento experiencias es casi una «obsesión», siendo uno de los grandes reproches que en su libro hará a los autores que le precedieron en publicaciones sobre California, como por ejemplo los jesuitas de la Noticia de la California, publicada en $1757^{11}$.

Su informe se referirá pues, al Departamento del norte, el que abarca «desde San Francisco Xavier hasta la última frontera, que comprenderá poco más o menos 250 leguas», o sea unos 14.000 kilómetros del Camino Real a lo largo del cual estaban, de Sur a Norte: nueve establecimientos del tiempo de los jesuitas (la Misión y Presidio de Loreto, San Francisco de Borja, Santa Gertrudis, San Ignacio, Nuestra Señora de Guadalupe, Santa Rosalía de Mulegé, La Purísima Concepción, San José y San Francisco Javier), el establecido por los franciscanos (San Fernando Velicatá) y los tres fundados por los dominicos (San Vicente Ferrer, Santo Domingo y Nuestra Señora del Rosario). «Nada digo sobre los nuevos establecimientos y Misiones del sur porque no los he visto, aunque no dejan de referirse bastantes miserias»; frases que por una parte se refieren a las erigidas por los franciscanos en Alta o Nueva California a partir de 1769 y por otra a las sureñas: Todos los Santos, Santiago y San José del Cabo.

Además, es el pronunciamiento más extenso y global de los elaborados en aquellos momentos por sus compañeros en las otras Misiones. Es de una claridad meridiana y manifiesta un gran pesimismo, desencanto y posiblemente frustración, como los de todos sus combarcanos. Y es que muy pronto tomaron conciencia de que aquellos territorios no satisfacían para nada sus expectativas no sólo en cuanto a lo espiritual sino también a lo temporal, de lo cual eran bastante conscientes sus predecesores franciscanos al dejárselos. ${ }^{12}$

11 Cf. p.e. Noticias, I 2.3 (corregir inexactitudes); I 2.3.6 (conocimiento directo suyo).

12 Cf. los diversos informes, tanto de 1778 como de 1783, transcritos en A. B. NIESER, Las fundaciones, 353-413; y nuestro trabajo: «Franciscanos y Dominicos en la Baja California», en Historia16 (279) 54-59. 
La tesis, que se esforzará por probar es la siguiente:

«La California por cualquiera parte que se mire, ya sea en general, ya en particular, no manifiesta otra idea que de hambre, desnudez, miseria y muy pocas proporciones para salir de tan infeliz estado».

Comienza señalando dos realidades, que entre otras, hacen la «felicidad» de los pueblos ${ }^{13}$ : la abundancia de bienes y su segura posesión. Pero si se intenta detectarlas en Baja California, la búsqueda es infructuosa.

Si se analiza su naturaleza sólo se constata:

«su miseria y desdicha; sus cortos bienes, cuya mayor parte están expuestos a mil contratiempos; la insubsistencia de las aguas; las epidemias - más que ordinarias - de chahuistles, gusanos, vientos, etcétera, con otros accidentes indispensables.

[...Y si se observan sus actuales Misiones] que son la parte considerable de la Provincia o que verdaderamente la constituyen, ¿qué otra cosa se verá en ellas que miserias y desdichas? ¿Qué altos y bajos no han padecido desde sus principios? Desde que hay Misión, no han hecho otra cosa los naturales que trabajar y no han producido ni producirán sus sudores otro que un líquido de trigo y un poco de pozole con alguna carne en algunos días».

Un poco más adelante señalará: «no se puede aspirar a más que al pozole, atole y un cotón por braguero». Y todo ello con el trabajo del común y el permanente esfuerzo del misionero, quien si llegase a faltar al poco tiempo volverían los indios a su modo de vida anterior por su «natural desidia», la insuficiencia de frutos y las escasas provisiones - carne, sebo, manteca, etc.- que se mandaban desde la otra orilla del Golfo (costas de Sonora y Sinaloa), aludiendo a los preceptivos envíos que debían recibirse de la «otra banda», como ocurría en época de los jesuitas y franciscanos ${ }^{14}$.

13 Sobre esta concepción económica de la «felicidad» y de sus otras dimensiones en los pensadores de aquel siglo, cf. J. A. MARAVALL, «La idea de felicidad en el programa de la Ilustración» (1975), publicado en la recopilación de sus Estudios de la historia del pensamiento español (siglo XVIII). (Madrid 1991, 162-189); P. AlVAREZ DE MIRANDA, Palabras e ideas: el léxico de la Ilustración temprana en España (1680-1760) (Madrid 1992, 271-300).

14 Un plan, que no se realizó a pesar de que los dominicos lo solicitaron reiteradas veces, preveía que para tales efectos se les entregasen dos Misiones en la otra orilla -en la Provincia de Sinaloa y de Ostimuri respectivamente- como tenían sus predecesores (cf. S. BERNABEU ALBERT - C. ROMERO ROMERO, «El cambio misional en la Baja California (1773): aspectos socioeconómicos y culturales», publicado en Actas del I Congreso Internacional sobre Los Dominicos y el Nuevo Mundo. Madrid 1988, 569-570). Sobre el sistema misional jesuítico de Sonora, cf. I. del Rio, Conquista y Aculturación en la California jesuítica. 1697-1768 (México 1984, 61 y ss); sobre el sistema misional franciscano en la misma región, cf. P. ESCANDON, «Los problemas de la administración franciscana en las Misiones sonorenses, 1768-1800», publicado en Actas del IV Congreso Internacional sobre Los Franciscanos en el Nuevo Mundo. (Madrid 1993, 277-291).

Actas del I Congreso de Historia de la Iglesia y el Mundo Hispánico Hispania Sacra 53 (2001) 
Así pues, utilizando una gráfica expresión de un contemporáneo suyo, a aquellas gentes de Baja California «no les sobra más que hambre».

Prosigue el informe del valenciano:

piénsese el arbitrio que se quiera; su adelantamiento, en mi sentir - atendidas las circunstancias de los tiempos, la condición de la tierra y propiedades [o características] de sus naturales- lo hallo casi imposible. Lo más que podrá lograr la suma vigilancia del que los gobierna es que no se acaben las Misiones y se siga la misma miseria. Porque si a los principios - que era corta la tierra descubierta, poca la tropa de afuera y las sementeras de afuera de algo razonables - apenas se veía en sus naturales más que desdichas; hoy en día - en que las sementeras se han menoscabado, pocos los abastos, más la tropa y mucha la tierra que se ha abrazado- ¿qué habremos de discurrir?».

A continuación analiza los mencionados campos de cultivo y el movimiento demográfico. De los primeros, generalmente «depende la subsistencia de la Misión» y se verá que, casi todas, subsisten por el beneficio de alguna presa [de agua] expuesta a los furores de los temporales que, en pocas horas, acaban con el trabajo de mucho tiempo, como lo ha acreditado la experiencia». En la Misión en la que estaba, efectivamente la había y el área total cultivada era probablemente de 83 hectáreas, donde se plantaba: maíz, trigo, frijoles, etc. De cebada, «se cosecharon 2.400 litros en 1782 , y no se registró nada más hasta 1801 . Con tan poca cebada y tanto maíz, y con mucha tierra y agua para riego, parece poco probable que se intentara el cultivo de secano en los días de la Misión» ${ }^{15}$.

La zona estaba bastante bien provista de pastizales y por eso sus rebaños tuvieron un progresivo aumento. Así en el período de la estancia de Sales, la manada de vacunos y el rebaño de ovejas, de 56 y 114 cabezas respectivamente, pasó a 170 y 603; las cabras sólo de 27 a 31, pero las bestias de carga de 6 a 76 cabezas (llama la atención que no aparezcan datos sobre cerdos, a diferencia de otras Misiones) ${ }^{16}$ Por otra parte, no debe olvidarse que estaba demasiado lejos de la costa —dieciséis kilómetros- para depender demasiado de los alimentos marinos, como por ejemplo los muy abundantes mejillones y abulones.

Continúa el documento que estamos comentando:

«si la mucha gente de que antes abundaban las Misiones apenas las ponían en el mismo estado [con sus trabajos], hoy en el día en que las epidemias continuas han acabado con la mayor parte de sus naturales en las Misiones antiguas, ¿qué esperanza puede haber en semejantes ocurrencias?».

15 P. MEIGS III, La frontera misional dominica en Baja California. (Mexicali 1994, 162).

16 Cf. Cuadro estadístico publicado por P. MEIGS III, La frontera, 290. Según Nieser si las cifras son bastantes aproximadas tendríamos expresada la causa principal de la posterior decadencia de esta Misión, pues sus abundantes rebaños habrían consumido toda la yerba y por ello facilitado la erosión en la tierra de pastos (cf. IBID., Las fundaciones, 158).

Actas del I Congreso de Historia de la Iglesia y el Mundo Hispánico Hispania Sacra 53 (2001) 
En el caso concreto de San Vicente Ferrer, su mayor población fue de 317 indios en 1787, por tanto seis años después de su fundación. La mayor afluencia de conversos parece haber ocurrido de 1782 a 1785 cuando la población pasó de 83 a 257 habitantes. ${ }^{17}$ Son los momentos posteriores a la gran epidemia de viruelas, en los que con toda probabilidad los fallecimientos fomentaron los bautismos; ${ }^{18}$ años en los que nuestro valenciano estaba en ella. Pero tampoco debe olvidarse que Baja o Antigua California fue sufriendo un lento pero constante declive en favor de Alta o Nueva California, gracias al apoyo que esta última recibió de las autoridades virreinales y peninsulares por motivos de estrategia geo-política y al aumento de cosechas y ganados; todo lo cual se fue manifestando en un incremento constante de población tanto en los establecimientos misionales franciscanos como en los Pueblos y Presidios que se fueron fundando.

En el párrafo siguiente Sales hace constataciones que no son meramente retóricas y en las que además subyace una velada respuesta a las acusaciones al respecto de los detractores del régimen misional como veremos más adelante.

«Lo que la Misión puede suplir es poco; dejar de trabajar es dejar de haber Misión; hacerlos trabajar parece injusticia; y si la Misión no tiene con qué poderlos mantener a todos, como en muchas sucede todos los años, ¿qué hará?. Tenerlos en la Misión es imposible; despacharlos a los montes es dar ocasión no sólo para que olviden lo que es gobierno, civilización y racionalidad, sino también para que acaben con los otros bienecitos de la comunidad, a saber: bestias mulares, caballos y ganados».

Después señala que en las Misiones de la Frontera se ve obligado «el misionero, por la suma hambre y desdicha, no sólo a no admitir gentiles para instruirlos sino también a despedir a los ya instruidos y cristianos» ${ }^{19}$.

Esto se denominaba visitas alternadas de los indios a las Misiones, dada la escasez de comida y la necesaria salida periódica para ir a buscarla (recolecta

17 Cf. cuadro estadístico publicado por P. MEIGS III, La frontera, 292.

18 Por citar un ejemplo, en la franciscana Misión Santa Clara de Alta California, fundada en enero de 1777, «los Padres estuvieron cinco meses sin bautizar a nadie. Durante el mes de mayo vino una epidemia en la que murieron de golpe numerosos niños indígenas de las aldeas de alrededor de la Misión. En búsqueda de un remedio rápido, 54 niños se sometieron al bautismo del 6 al 22 de junio de aquel año» (S. BRANDES, «Las Misiones de la Alta California, como instrumentos de conquista», publicado en De palabra y obra en el Nuevo Mundo. T.2. Madrid 1992, 162)

19 Años después en su libro, al hablar de Misión Santa Gertrudis, señala que a sus indios cuando «no los puede mantener, los echa a los montes y esto es muy regular: Vd. podrá inferir qué progresos se podrán esperar de estas proporciones» (Noticias, II 41). Sin olvidar que a veces por tal carencia de alimento «se veían precisados a robar de la Misión o ir a la fuga», empleando expresiones de la época. 
silvestre), que ya practicaban los jesuitas. ${ }^{20}$ Lo ideal era que los indios permanecieran en las Misiones, pero dado que por las precariedades existentes no podía ser así, con estos contactos - repetidos y constantes- se esperaba que fueran asimilando rasgos y comportamientos propios de las sociedades sedentarias y fueran abandonando poco a poco sus antiguas costumbres. En las Misiones, además de adiestrarse en cierto tipo de actividades productivas, se sometían a un orden social ajeno al de su propia tradición cultural de cazadoresrecolectores: aprendían a vestirse, a vivir bajo techo, a cultivar la tierra y criar ganado, a realizar labores artesanales y, en fin, a obrar conforme les indicaban los misioneros.

Un artículo de las Instrucciones del Padre Hidalgo de 1781 indicaba que «[debe darse] de comer a todos los indios quando vienen a ellas de los montes sus respectivas semanas» y otro señala que se les envía a «los montes, donde por falta de alimentos es preciso despacharlos a vivir». ${ }^{21}$ Incluso, como el mismo Sales en su informe señala, cuando había hambrunas entre la población indígena no reducida, «se echa mano de las Misiones, viéndose éstas tal vez obligadas a despedir a sus naturales al monte, ${ }^{22}$ como en estas fronteras ha sucedido, poniéndose unos en trabajo de los otros», aludiendo a la obligada subsidiariedad de los cristianizados con los que no lo estaban todavía.

Después se presunta nuestro valenciano:

20 Cf. S. BRANDES, «Las Misiones», 165-166; I..del RIO, Conquista, 135-136; IBID., «La guerra de la Chichimeca y la Misión de la Baja California», publicado en De palabra, 188

21 A.G.I., Guadalajara 586, Ordenes,..., $59^{\circ}$, f. 5r. (reparto de alimentos y vestidos); $70^{\circ}$, f. $6 \mathrm{r}$ (visitas alternadas y reparto comida) y $66^{\circ}$, f.6 (recolecta silvestre); cf. Noticias, III 60-64. El Padre Presidente, Vicente de Mora señalaba en 1777 al Virrey Bucareli que los indios de la Misión San Francisco Javier «se ven obligados la mayor parte a buscar la comida por los montes, concurren de ocho a ocho días, y cuando más, de quince a quince días, a la Doctrina y a Misa. Pero el no estar permanentes en su pueblo y, el andar de esta manera no proviene de falta de habitaciones, porque, aunque esta Misión y las demás estuvieran más pobladas de casa y de palacios que Roma, siempre andarían de esta suerte como no tuvieran pan dentro de las mismas poblaciones, porque con las puras casas no se mantienen los hombres» (IBID., Informe, Loreto 20.2.1777, transcrito en A. B. NIESER, Las fundaciones, 329).

22 Andrés Souto, en su informe desde San Francisco de Borja, escribe: «tiene esta Misión 666 individuos, de los cuales no puede mantener más que 100, dándoles un poco de harina cocida o grano cocido con agua, por ser escasas las cosechas, las aguas y débiles las tierras [...], por cuyo motivo andan por los montes buscando la vida con la precisión de comer ratones, lagartijas, hasta el excremento en ciertos tiempos [...] Muchos de ellos no vienen a la Misión en muchos años por buscar el alimento para vivir y no padecer mayor miseria; y por tanto carecen de la instrucción de la doctrina cristiana» (A.G.N., Provincias Internas, v.1. exp. 11, f. 352), la alusión del final se refiere a la denominada segunda cosecha» o «de repaso», en la que los indios separaban de sus excrementos las semillas de pitahayas no digeridas, con el fin de comerlas luego una vez tostadas y molidas, posiblemente para sobrevivir en períodos de sequía prolongada (cf. I. del RIO, Conquista, 32-33 n.19).

Actas del I Congreso de Historia de la Iglesia y el Mundo Hispánico Hispania Sacra 53 (2001) 
¿Pues, cómo saldrán de esta infelicidad?. Y a más de esto, ¿cómo se cubrirán sus carnes? ¿Dónde se sacarán herramientas para la subsistencia de las labores y utensilios para la Misión? ¿Pudieran jamás presentarse con decencia, ni continuar sus siembritas si los misioneros, movidos de caridad, no encargaran, a cuenta de sus sínodos, lo necesario para ir pasando con esta misma miseria?».

La utilización por parte de los misioneros del sínodo para solventar necesidades que no eran propiamente suyas, fue bastante habitual y así nuestro valenciano lo hizo, como ya hemos visto. En otro de los informes se indica que «fuera de lo que empleamos en nuestras necesidades religiosas, todo lo restante [del sínodo] lo empleamos en [comprar para vestir a los indios] paño y bayeta, sayal y manta».23 Pero ¿y si se recurriese a los bienes bien de los mismos establecimientos, bien de los de los mismos indios no-reducidos (que en su libro denominará gentiles), o de los indios reducidos (que llamará medio racionales)?:24 quizá se paliaría algo la situación, pero nada más.

Los posibles bienes de las Misiones provenían por una parte, de ciertas obligaciones que la Corona tenía por el Patronato Regio ${ }^{25}$ y, por otra, de los permanentes esfuerzos de los misioneros. Una de las motivaciones esgrimidas para la pretendida reforma de los Regulares coloniales por parte de los Borbones era su gran acopio de bienes y una de sus fuentes eran las Misiones. ${ }^{26}$

23 Transcrito por A. B. NIESER, Las fundaciones, 400. cf. 409. En diversas ocasiones Sales indicará en su libro que los misioneros proporcionaban algunas ropas (cf. Noticias, II 58. 101); los franciscanos -por lo menos en sus establecimientos de Alta California- daban cada año a los indios una manta y una blusa larga y ancha (cf. S. BRANDES, «Las Misiones», 164; este autor deja en el aire la válida pregunta sobre si ello no era una de las causas de la aceptación del Bautismo por algunos, pero tampoco debe olvidarse el ancestral «horror» de los misioneros, y, también de los «civilizados» ilustrados, al desnudismo de los indios

24 Para las denominaciones y las correspondientes distinciones en los tipos de indios. por ejemplo cf. Noticias, I 37. En 1778 sus combarcanos que estaban al frente de San Fernando, propusieron «que en ella se establezca una o dos familias de razón [criollas o europeas], porque estos indios, como neófitos, necesitan de instrucción o director en todas las faenas de campo y demás que en las Misiones suelen ocurrir» (transcrito por A. B. NIESER, Las fundaciones, 396; el subrayado es mío).

25 El valenciano informará que para cada nueva fundación «el Rey consigna mil pesos duros y de éstos saca el misionero para herramientas, calderos, ollas, \&c. Lo perteneciente a la Iglesia lo envía el Señor Virrey de los espolios los Padres Expulsos que asistían en México. Pero si el barco que trae todo lo necesario se pierde, como sucedió dos ó tres años, entonces se aumentan los trabajos por la falta de víveres y ropas, no sólo a los indios, sino más principalmente a los misioneros» (Noticias, III 63)

26 Cf. por ejemplo L. MERINO, «Las 'Noticias secretas de América' [de J. Juan y A. de Ulloa] y el clero colonial (1720-1765)», en Missionalia Hispanica XIII (1956) 5-82. 193-254. 385-452. Para México, cf. N. M. FARRISS, La Corona y el clero en el México colonial. 1571-1821 (México 1995; quien se basa fundamentalmente en los informes del arzobispo de México F. A. de Lorenzana y del obispo de Puebla F. Fabián y Fuero, contemporáneos de Sales)

Actas del I Congreso de Historia de la Iglesia y el Mundo Hispánico

Hispania Sacra 53 (2001) 
El Padre Vicente de Mora en 1777, ante las acusaciones a este respecto contra los dominicos, escribía: 27 «Las Misiones, con sus productos y haberes, no las reputan los Padres como fincas de sus Conventos, sino como posesiones propias que son verdaderamente de los mismos naturales y el que una Religión las administre no es quitarles a los indios su derecho ni da fundamento alguno para juzgar que los misioneros son dueños absolutos de ellas, porque aquí no se ha tenido, ni tiene, más señorío ni dominio que el que permite el oficio de tutores de los indios, cargo de Procuradores de estos pobres: que todo está reducido a cuidados y fatigas solamente, ya en distribuirles el pan cuando lo tienen, ya en conservar sus haberes y aumentar lo que se puede y, finalmente, en trabajar por todo el bien de sus hijos como padres. Y hasta el pan que con tantas amarguras hemos comido y comemos, se ha satisfecho y se para tan cabalmente que ni un medio se les debe, porque de los sínodos - que la piedad del Soberano nos dispensa - costeamos hasta el barbero y lavandera y esto sin entrar en cuenta las cortas limosnas que no's han hecho los fieles o por la caritativa y piadosa justicia del servicio del altar o benevolencia y gratitud que a varios amigos debemos algunos Padres. Y si lícito me fuera contar en esta satisfacción el trabajo que nos cuesta la administración de lo económico, aunque toda la California se vendiera, siempre quedaría alcanzada; pero nos es tan injusto, como indecoroso ciertamente a nuestro estado, la más leve recompensa de un trabajo que, siendo por caridad bien parecido, sufrido por cualquier interés es en todo religioso muy mal visto. Los misioneros se surten de sus sínodos y los gastos de Misiones no se hacen a beneficio del Padre, ni aquí se ocupan los naturales a trabajar para el Padre, como en otras Misiones o Curatos acontece. En una palabra, los trabajos de comunidad en Californias no han atendido ni atienden en nuestro tiempo a otro objeto que a la utilidad propia de los indios. El seguir trabajando de común es porque de otra manera no pueden conservarse y menos adelantar su propia hacienda ${ }^{28}$.

Pero también había ciertas diferencias entre los establecimientos misionales, no sólo por el tiempo transcurrido desde su creación, sino también por la

27 Este amplísimo documento responde vehementemente a un conjunto de acusaciones que se habían hecho sobre la gestión de los dominicos; algo más de un año después comisionó a Nicolás Muñoz «para representar a su nombre ante la superioridad de Vuestra Señoría [el Comandante General] lo que juzgue necesario y conveniente a la subsistencia y fomento de dichas Misiones», presentando un amplio documento que en 45 puntos sugiere medidas concretas en la misma línea (San Miguel de Horcasitas 24.11.1778, transcrito en A. B. NIESER, Las fundaciones, 353-394).

28 IBID., Informe , 335-336. También dice más adelante: «No son sirvientes los Padres del Gobernador; son. sí, siervos por su empleo y ministerio de Jesucristo y vasallos de su Rey, y el administrar en lo temporal a estos infelices es por Dios y por el Rey, cuya Majestad se dignó honrarnos con su confianza en tan piadoso servicio. Más este honor, de que tanto nos gloriamos, se ha pretendido denigrar por el Gobernador don Felipe Neve, juzgando o poniendo en duda la fidelidad y verdad de los misioneros dominicos de California» (pp. 351-352). 
diversidad de posibilidades de los lugares en que estaban erigidas cada uno y así Sales afirma que «es también cierto que así como las hambres y miseria — sin pasar la línea de miserias- suelen ser menores en algunas Misiones antiguas, así también son mayores en las fronteras». De ahí que por ejemplo ya en las Ordenaciones dictadas por el Padre Mora en 1774, se mandase a los Superiores pertinentes «subministren todo lo conducente a la subsistencia de los Ministros de la Frontera, en la que he tocado por experiencia una gran carestía, no sólo de las precisas temporalidades para su conservación [... Advirtiendo además] que a los contraventores de esta mi ordenación se les aplicarán las correspondientes penas, por ser contra toda equidad que entre Ministros de igual mérito e hijos de un mismo Padre, padezcan los unos necesidades, teniendo hermanos que la pueden subvenir, suponiendo que este mutuo socorro se entiende para con todas las Misiones y sus Misioneros» ${ }^{29}$

Y nuestro valenciano al entender como incontrovertible todo lo que ha venido señalando hasta el momento, se pregunta conociendo la negativa respuesta:

«ise podrá enajenar alguna suma abundancia, felicidad o riqueza de la Provincia, se podrían discurrir algún tráfico comercio, realaje u otros ramos, [de lo] que pende la felicidad de los pueblos?».

Pero es que además, no debe olvidarse la precariedad de la «pacífica posesión» de todo. Y es que

«ni Misiones, ni sus bienecitos, ni tropas, ni cuanto hay en la California, deben reconocer otra causa de su permanencia, después de Dios, que la voluntad de los indios naturales. En el día en que se les quite el velo con que están cubiertos y quieran exterminarnos, nadie podrá disputarles su resolución. Nuestras fuerzas son muy inferiores y ellos pelean con la multitud. Hasta ahora la experiencia ha acreditado (aunque parece contra la caridad y justicia) que sólo la sujeción y reducción los ha atado las manos, como a hijos del temor. En el día en que adviertan demasiada condescendencia y extraordinaria libertad, y que esto se les permite por el recelo que les tenemos, será suficiente para el exterminio».

Y vuelve a distinguir la situación de unas Misiones y otras al respecto. Las antiguas no generan tanta preocupación dado el escaso número de indios. Pero en las de la Frontera es otro asunto por diversos factores:

29 A.G.I., Guadalajara 513, Copia, $2^{\text {a }}$, f. 1r-2; a este socorro mutuo se refiere el artículo 97 de las del Padre Hidalgo y Noticias, III 61.

Actas del I Congreso de Historia de la Iglesia y el Mundo Hispánico

Hispania Sacra 53 (2001) 
«los [indios gentiles] vecinos que nos rodean; los acontecimientos funestos del [río] Colorado y todas sus circunstancias; 30 la poca tropa que de ordinario suele haber y ésta mal montada; la poca esperanza de socorro en las Misiones vecinas por la misma razón, con otras infinitas circunstancias que son bastantemente visibles, y se verá que, siempre que cuando quieran atacarnos y hacer alguna irrupción, nadie podrá oponerse con juicio y fundamento de salir con bien».

\section{Y concluye su argumentación:}

«luego, es preciso que hagamos algún concepto formal de que esto subsiste porque subsiste, nada más».

Finalmente hace dos breves consideraciones, que por otra parte expresan una vez más cómo él también es hijo de su tiempo.

En cuanto a «la piadosa intención de nuestro Católico Monarca [por] la reducción de pueblos, reconocimiento al gobierno y civilización política, [...] no hay Provincia más infeliz, ni tierra menos proporcionada» ${ }^{31}$. Pero no recurre al argumento de «la fidelidad de mi hábito [los Dominicos] al Soberano y la natural que me acompaña de vasallo», empleando expresiones de la época; en su libro si lo hará ${ }^{32}$.

Y su segunda consideración consiste en señalar «la desidia de sus naturales, su aversión a cosas de reducción y natural apetito al monte [..., pero no debe

30 Se refiere a la reciente rebelión de los yumas, en 1781, episodio de escaso interés militar pero de importantes consecuencias (cf. L. NAVARRO GARCIA, «la expansión hacia el Norte de México durante la segunda mitad del siglo XVIII: geopolítica y política indígena», publicado en La América Española en la Epoca de las Luces. Traadición - Innovación -Representaciones. (Madrid 1988. 225-226).

31 Similar constatación, por ejemplo, hacía en 1777 el Presidente de estos frailes: «la tierra de las antiguas misiones de Californias es para nada buena y que sólo la piedad de nuestro Rey, por celo de la Religión Católica, la pudiera sostener, como por la misma causa mantiene otros páramos también que no le sirven de nada» (V. de MORA, Informe, 333).

32 El varias veces citado Padre Mora sí la esgrimía así como alguna de sus consecuencias: «Además de atropellar, no sin gravísimo escándalo la Ley de Dios, se quebranta expresamente las justas leyes del Reino por el perjuicio que ya se deja entender de no pagar como es justo el valor del trabajo de estos vasallos [los indios californios] que, como aislados y sin ningún dinero, ni tienen facultad para pedir su derecho ni aun voces para clamar misericordia a otro Rey que al de los Cielos, si no es que los eclesiásticos ocurren a Vuestra Excelencia [el Virrey] dando parte de injusticias en debido cumplimiento de lo que el Rey les ordena por sus leyes. El Rey ni tiene ni quiere la más leve utilidad de la sangre de los pobres. Su voluntad soberana repugna que sus Erarios se aumenten por términos tan injustos y con tanto perjuicio de sus vasallos; no digo en la sujeta materia que hasta me causa rubor nombrar por ella a mi Soberano. Pero, ni por todos los intereses del mundo, permite el imaginar de tan alta majestad lo que, aun de cualquiera hombre de bien, me es ilícito pensar. En una palabra, nuestro Monarca Católico no quiere más intereses que la propia utilidad de sus vasallos y provecho de sus Reinos» (IBID., Informe, 339-340)

Actas del I Congreso de Historia de la Iglesia y el Mundo Hispánico Hispania Sacra 53 (2001) 
olvidarse que] no hay tierra más abundante, ni Provincia más feliz, porque en cualquier parte y sin cultivo, hallan sus naturales raíces para comer, más o menos, según los terrenos y temporales». ${ }^{33}$

Concluyendo con esta advertencia sobre su pronunciamiento:

«En lo que llevo dicho nada comprendo sobre lo espiritual pues [lo temporal], al paso que es asunto más delicado, ofrece también mayor campo no sólo para que se vean las condiciones de los naturales, sino también para que se conozcan los imponderables trabajos de los misioneros».

Y es que - como escribirá en su libro ${ }^{34}$ — «la otra pesadísima carga que tiene el Misionero es el cuidar de lo temporal»; y en el párrafo anterior ha dicho: «el Misionero es el Padre, la Madre, el Criado, el Juez, el Abogado, el Médico y quantas castas de artesanos hay en el pueblo. Nada se emprende, nada se determina, que no sea según la dirección del Misionero».

Sin embargo, no debe olvidarse que esta tarea en aquel tiempo no era del todo bien vista por algunas autoridades y pensadores por muy diversas razones ${ }^{35}$. Y en este rechazo, coincidían con eclesiásticos y religiosos que desde comienzos de aquel siglo limitaban a los misioneros al campo exclusivamente espiritual, sin funciones de otra índole por considerarlas impropias de su ministerio ${ }^{36}$.

Antes de terminar esta década del 80 se manifestará con toda intensidad el desinterés de la dominicana Provincia de Santiago de México por estas Misio-

33 Esta visión de los indios es común a la gran rnayoría de pensadores españoles y extranjeros (p.e. cf. F. L. JIMENEZ ABOLLADO, «Visión del indio en los viajes por el Norte de la Nueva España en el siglo XVIII», publicado en VII Congreso Internacional de Historia de América. II. España en América del Norte. Zaragoza 1998, 1053-1060; U. BITTERLI, Los «salvajes» y los «civilizados». El encuentro de Europa y ultramar. México 1982, 151-186; J. BESTARD y J. CONTRERAS, Bárbaros, paganos, salvajes y primitivos. Barcelona 1987, 219-277).

34 Noticias , III 56.54-55. El que estaba al frente de Misión Santa Gertrudis, Juan Formoso, en este mismo 1783 informa que los misioneros «aquí hacemos de ministros apostólicos y, juntamente, de mayordomos. arrieros, vaqueros, pastores, labradores, padres de familia y tutores por cuanto todo lo espiritual y temporal están a nuestro cargo» (transcrito en A. B. NIESER, Las fundaciones, 408).

35 Cf. nuestro trabajo: «El siglo XVIII español ante el hecho misional americano», publicado en Cristianismo y culturas. Problemática de inculturación del Mensaje Cristiano. Actas del VIII Simposio de Teología Histórica (Valencia 1995, 295-319).

36 Cf. P. Borges, Misión y Civilización en América. (Madrid 1987. 198-225). El P. Vicente Mora ya en 1777 afirmaba que si se tomaban ciertas medidas en relación con los indios, que ha solicitado ya varias veces, «nosotros conseguiremos la paz que tanto deseamos y, desprendidos de este tan grave embarazo [por lo material], atenderemos mejor al cuidado de la Iglesia y de las almas, que es el fin a que fuimos convocados y no a cuidar de otra cosa» (IBID., Informe, 336).

Actas del I Congreso de Historia de la Iglesia y el Mundo Hispánico

Hispania Sacra 53 (2001) 
nes, como claramente se denunciará. ${ }^{37}$ Para fines prácticos, eran una bastante autónoma Vice-Provincia, a excepción de las finanzas. Los misioneros habían sido reunidos en Europa y enviados a la península californiana y estaban al servicio del Rey. Pero el grupo original estaba exhausto y los veteranos deseaban un relevo. Había que conseguir hombres de España o de la Provincia o abandonar las Misiones. No estoy del todo de acuerdo con que todo indique que en este tema, «la Provincia deseaba mantenerse independiente de la Corona» así como «que la Provincia no podía aceptar las Misiones en los términos del Rey, por el riesgo de caer bajo un cierto control de la Corona. ${ }^{38} \mathrm{Me}$ inclino a pensar que todo ello está más bien relacionado con la ya señalada constatación de los «dominicos europeos» de que aquellos territorios no satisfacían para nada las expectativas, no sólo en cuanto a lo espiritual sino también a lo material, exigiendo afrontar graves precariedades. Sin olvidar además, que estamos ante una expresión de las tormentosas relaciones de los «dominicos europeos» con los «dominicos americanos»:

Hasta aquí esta presentación de un poco conocido documento de la década de 1780 de un misionero dominico valenciano, en el que brinda una bastante ajustada visión de las pobrísimas tierras y gentes de Baja California en aquella época, coincidente con la de sus contemporáneos y que mantendrá en el interesante libro que publicará años después.

37 Cf. Informe de M. Hidalgo al Virrey (México 2.8.1791), en A.G.N., Misiones, v.5, exp.4, ffol. 66-71v., transcrito por A. B. NIESER, Las fundaciones, 414-421; lo he estudiado en mi «Los 'dominicos europeos»'.

38 A. B. NIESER, Las fundaciones, 180.

Actas del I Congreso de Historia de la Iglesia y el Mundo Hispánico Hispania Sacra 53 (2001) 